\title{
Foro abierto
}

\section{de opinión}

\section{AL RESPECTO DE LAS ACCIONES PROPUESTAS POR LA COMISIÓN INTERDISCIPLINARIA DE EXPERTOS DE VIOLENCIA DE GENERO}

\section{ABOUT THE ACTIONS PROPOSED BY THE DISCIPLINARY COMMITTEE OF EXPERTS OF GENDER VIOLENCE}

Por Leandro D. Dionisio $\left(^{*}\right)$

(*) Médico psiquiatra, Jefe del Departamento de Salud Mental de la ESP/FCM/UNC
SOBRE AS ACÕES PROPOSTAS PELA COMISSÃO DISCIPLINAR DA PERITOS DA VIOLÊNCIA DE GÊNERO

En el mundo desarrollado; desde la epidemiologia hasta las ciencias económicas han comprendido la importancia de incluir a las ciencias del comportamiento para promover e impulsar acciones más eficaces en sus propios campos disciplinarios. En la Argentina, pareciera que las ciencias jurídicas aún no. El Gobierno de la Provincia de Córdoba anuncia como un gran avance en la lucha contra la "violencia de género" el proyecto presentado por el comité de expertos, entre los cuales no se observa un solo miembro que provenga del campo de las ciencias de la conducta. 
¿Acaso creemos que solo con normativas y más ejercicio represivo vamos a revertir las estadísticas que nos muestran cada vez más muertes?; ¿Qué el sistema judicial va a poder actuar preventivamente?; ¿Qué con multas o talleres de reflexión educativa vamos a cambiar conductas agresivas que están arraigadaso promovidas por el mismo sistema que pretende atacarlas?

Canadá y España son los países que más desarrollo de estrategias preventivas, de detección precoz, así como asistencia a agresores y víctimas han realizado. En estos países, así como en todos los ámbitos de estudio de las ciencias del comportamiento, ya se conoce cómo se inician las relaciones conflictivas de pareja, el rol enorme que juegan en ello las dimensiones de la personalidad de los sujetos, que la violencia de género es solo un subtipo de las distintas razones que producen y sostienen a la violencia de pareja, que el alcoholismo juega un rol preponderante, que en violencia intrafamiliar también está creciendo la violencia de hijos contra padres y así sucesivamente. Continuar excluyentemente con solo la judicialización de esta problemática, lamentablemente no resolverá nada, sino que lo acrecentará. Al amparo de esta modalidad de abordaje crece la denuncia falsa, la lucha entre sexos, el miedo al escarnio público de los funcionarios judiciales que no actúan y toda una serie de acciones por medio de las cuales depositamos toda la responsabilidad de la violencia en un otro.

Los vínculos patológicos que sostienen estas prácticas, en todas sus graduaciones pueden ser modificados, en la medida en que podamos reconocerlos como presentes en nuestra propia individualidad, así como en nuestro seno familiar, institucional e incluso social. La violencia no está fuera de nosotros, sino que convive con nosotros.

Por ello de lo que se trata aquí, es de ser conscientes y responsables de tal manera de facilitar:

1. Mensajes públicos que promuevan las relaciones saludables, al menos en igual cantidad que los que se destinan al consumo de alcohol,

2. Protocolos de actuación en todas las escuelas y servicios de salud, de tal manera que sus profesionales estén preparados para detectar conductas agresivas en forma temprana,

3. Escalas de riesgo validadas en el ámbito judicial que permitan detectar si un sujeto es capaz de aumentar sus niveles de violencia o no,

4. Servicios especializados en diagnóstico y tratamiento de las distintas modalidades de la agresión para víctimas y agresores en toda institución de salud, pública o privada.

Solo con esto lograremos revertir la cantidad de muertes y lesiones que sufren miles de mujeres, niños y ancianos producto de hechos violentos. 